\title{
Effects of phonological similarity and concurrent irrelevant articulation on short-term-memory recall of repeated and novel word lists
}

\author{
VERONIKA COLTHEART \\ Macquarie University, North Ryde, New South Wales, Australia
}

\begin{abstract}
The extent to which phonological similarity of list words impairs short-term-memory recall was investigated in two experiments. Experiment 1 showed that the phonological-similarity effect occurred both when list words were repeatedly sampled from a small set and when they were new on every trial, both when word-order information was required and when it was not. Furthermore, the adverse effect of phonological similarity on recall was apparent on the initial lists recalled, did not change over trials, and cannot be attributed to increasing levels of proactive inhibition across lists. In Experiment 2, subjects were required to count repeatedly to six during list presentation. Concurrent irrelevant articulation lowered recall and abolished the phonologicalsimilarity effect for both repeated and novel word lists.
\end{abstract}

The view that short-term memory (STM) for briefly presented letters, words, or objects is chiefly dependent on a phonological (speech-based) code has been supported by a considerable body of evidence since the early studies of Baddeley (1966), Conrad (1964), and Wickelgren (1965). The evidence for phonological coding was that memory errors resembled the visually presented stimuli phonologically (Conrad, 1964) and that span for lists of acoustically similar letters or words was smaller than it was for unrelated or visually similar letters or words (Baddeley, 1966; Conrad \& Hull, 1964). From the age of 6 onward, children display phonological similarity effects on STM recall. They are worse at remembering lists of pictures of objects with similar names than they are at recalling those with dissimilar names (Hitch \& Halliday, 1983). Younger children's recall is adversely affected by visual similarity of to-be-recalled objects but is unaffected by phonological similarity (Hitch, Halliday, Schaafstal, \& Schraagen, 1988). This suggests that younger children use visual coding but not phonological coding in STM recall and that children only use phonological coding from the age of approximately 6 onward.

Deaf children are worse at recalling visually similar letters than they are at recalling phonemically similar letters, whereas children of similar age with normal hearing show the opposite pattern (Conrad, 1972). Congenitally speech-

\footnotetext{
This research was supported by a MURG grant to Veronika Coltheart. Preparation of this paper was supported in part by research facilities generously provided by the M.R.C. Applied Psychology Unit, Cambridge, England; the research discussions and support offered to visitors by Alan Baddeley, Karalyn Patterson, and their colleagues are gratefully acknowledged. The research assistance of Judi Leahy and Nancy $\mathrm{Dal}$ Cin is gratefully acknowledged. Correspondence should be addressed to Veronika Coltheart, School of Behavioural Sciences, Macquarie University, North Ryde, NSW 2109, Australia (e-mail: bh_coltheart@hope. ocs.mq.edu.au).
}

less children who can hear and comprehend speech are impaired at recalling pictures of objects with similar names, as are normal children (Bishop \& Robson, 1989). Thus, the ability to perceive speech input, but not to produce speech, is required for the development of the use of phonological coding in STM. Presumably the speechless children can represent phonemes even though they are unable to generate them in the form of overt speech.

With visual presentation of list items, phonemic similarity impairs recall in adults and older children, as stated above. When subjects are required to articulate irrelevant speech, for example, the, the, the ..., during list presentation, memory span is reduced and the phonemicsimilarity effect is abolished (Murray, 1968). However, if list presentation is auditory, the phonemic-similarity effect is not abolished. This led Baddeley, Thomson, and Buchanan (1975) to conclude that the phonemic-similarity effect arises from storage in a phonological short-term store to which speech input has obligatory access. Visual input must be phonologically recoded before it can access the phonological store, and concurrent irrelevant articulation prevents this phonological recoding from taking place. Of course, concurrent articulation must also interfere with, if not prevent, articulatory rehearsal of list items.

The articulatory rehearsal process is thought to underlie the word-length effect on STM span. The word-length effect refers to the finding that memory span is larger for short (e.g., monosyllabic) words than it is for long (e.g., polysyllabic) words (Baddeley et al., 1975). Concurrent articulation during list presentation abolishes the wordlength effect with both visual and auditory list presentation (Baddeley et al., 1975). This result was attributed to the functioning of a limited-capacity articulatory rehearsal loop, which can represent only a limited time interval of speech. The findings that digit span is smaller 
in Welsh than it is in English (Ellis \& Hennelly, 1980) and larger in Chinese than it is in English (Stigler, Lee, \& Stevenson, 1986) are consistent with the articulatory loop explanation. Welsh number names are longer and Chinese number names are shorter than those in English. A problem is posed by the finding that congenitally speechless children also show the normal word-length effect in recall of picture names (Bishop \& Robson, 1989). Recall was assessed by using an "eye-pointing" procedure: Children gazed in sequence at the list pictures in an array in front of them. This result suggests that the rehearsal process underlying the word-length effect must use an inner-speech phonological code available to those who have never been able to produce overt speech.

The phonemic-similarity and word-length effects on STM recall and their abolition by concurrent articulation are highly reliable and have been replicated many times (Baddeley, 1986). Different word sets and pictures of objects have been used in some of the studies, and so the effects are not specific to a particular set of verbal and pictorial items. In the studies on adults, a 1-sec rate of presentation is normally used, whereas with younger children, slower, 2-3 sec rates may have been used. A common feature of all of the research since Conrad (1964) has been that lists have been sampled from a limited pool of around 8-10 items. Thus, each 5-word list was randomly selected from a pool of 8 phonemically similar words or from a pool of 8 matched dissimilar words. In some experiments (e.g., Baddeley, 1966), the entire word sets were visible throughout the task. The subjects were required to recall the list in order of presentation and recalled items were scored correct only if recalled in their correct serial position. The rationale for presentation of lists selected from a small, familiar pool of items was based on the view that the phonological short-term store is a system that can primarily represent sequential information. Thus, imposing substantial demands of item encoding might obscure its functioning.

Although the findings of phonemic-similarity effects have been shown to be reliable, further research on memory for nonwords has indicated that more than one phonological code may be invoked in STM recall. Besner and Davelaar (1982) gave subjects visually presented nonword lists to recall. They manipulated phonemic similarity of list items and similarity to real words: nonwords (pseudohomophones) sounded like real words, or they did not. Phonemically similar lists were less accurately recalled than were phonemically dissimilar lists, and lists of pseudohomophones were better remembered than were lists of nonwords that did not sound like words. The phonemicsimilarity effect was abolished by concurrent articulation. The lexicality effect (superior recall of pseudohomophones) was not. Besner and Davelaar (1982) concluded that the pseudohomophone advantage in recall was produced by a phonological code used to achieve lexical access and that this differed from the code used to maintain information in STM. They found comparable effects with short and long (polysyllabic) pseudohomophones and non- words: Recall of pseudohomophones was superior to that of nonwords, and this superiority was maintained with concurrent articulation. A word-length effect was also found-better recall of short than of long pseudohomophones and nonwords-but this word-length effect was abolished by concurrent articulation. An alternative explanation is that the derivation of phonological codes is unaffected by concurrent articulation, but their maintenance or manipulation is impaired by it (Coltheart, Avons, \& Trollope, 1990; Monsell, 1987).

Earlier it was pointed out that these results have all been based on memory tasks in which a small, limited pool of items is repeatedly sampled to create memory lists. It can be asked whether the effects of phonemic similarity and word length of STM list items are specific to these conditions. Some recent evidence suggests they may be. La Pointe and Engle (1990) investigated STM span under various conditions. The findings of most interest for this paper were that word-length effects were obtained with lists sampled from small, fixed pools of items and that the word-length effect was abolished by concurrent articulation. However, when list words were new in every list, the word-length effect was maintained under concurrent articulation. This is a troublesome result for Baddeley et al.'s (1975) explanation of the word-length effect. If the word-length effect is produced by the articulatory rehearsal process, which is prevented or lessened by concurrent articulation, it is hard to see why in a task that demands both item and order encoding (because items are new on every trial) the superior recall of short words is maintained under concurrent articulation. La Pointe and Engle (1990) suggested that a third, different form of phonological code is invoked when items are new on each trial and that this code is resistant to the effects of concurrent articulation. This postulation of a third code seems rather unparsimonious.

However, recently in another paradigm, Bavelier and Potter (1992) also found evidence of a phonological code that was unaffected by concurrent articulation. They studied recall of rapidly presented printed lists of words or sentences shown at a 100-117-msec rate. Under these conditions, "repetition blindness" occurs for the second occurrence of a repeated word presented in close temporal proximity (Kanwisher, 1987). Repetition blindness refers to the diminished ability to recall both occurrences of a word; ordinarily it is the second occurrence that is omitted. Repetition blindness has been found when the second word was orthographically similar to the earlier one (Kanwisher \& Potter, 1990), and Bavelier and Potter (1992) found that it occurred for homophones of earlier words. They concluded that repetition blindness can arise from a phonological code and found that concurrent articulation had no effects on recall. They argued that phonological repetition blindness arises from an early phonological code used to register items in STM and that it differs from the (later) code on which STM recall is based and which is susceptible to concurrent articulation. However, it is also possible that the phonemic-similarity 
effect in STM recall is simply a function of the specific task conditions used in previous research.

\section{EXPERIMENT 1}

The experiments reported in this paper were designed to investigate whether the detrimental effect of phonemic similarity is observed when list items are novel on every trial and whether concurrent articulation affects the pattern of performance as it does when words are repeatedly sampled from a small, fixed pool of items. Experiment 1 investigated recall of phonemically similar and dissimilar words when list words were new on every trial or when they were repeatedly sampled from a small pool of eight words as in Baddeley's (1966) experiments. The similar (cat, mat, map...) and dissimilar (cow, day, bar... ) words from Baddeley's (1966) Experiment 1 were presented as the small pool of repeated items. Additional words were selected and used to construct similar and dissimilar lists of unrepeated words. The repeated and novel word lists were presented visually to two groups of subjects using a procedure similar to that in Baddeley (1966).

\section{Method}

\section{Subjects}

Thirty-two first-year undergraduate, fourth-year undergraduate, and postgraduate students acted as subjects. The first-year students received course credit for acting as subjects.

\section{Stimulus Materials}

Repeated word lists. The phonemically similar set of eight words (mad, man, mat, map, cad, can, cat, cap) and the dissimilar set of eight words (cow, day, bar, few, hot, pen, sup, pit) were from Baddeley's (1966) Experiment 1. These were used to select 10 phonologically similar and 10 dissimilar lists of five words each. No word appeared more than once in a list, and words occurred approximately equally often in the 10 lists.

Novel word lists. Fifty 3 -letter consonant- ' $a$ '-consonant words that matched the set of repeated words in frequency (Kučera \& Francis, 1967) were chosen. These included a limited set of 8 final consonants and 17 initial consonants (e.g., rat, lap, tab, fad ...) Fifty dissimilar words were selected that matched the similar ones in word frequency. The dissimilar words included all 5 vowels and used a varied set of initial and final consonants (e.g., mop, vet, cow, rum...). Only two pairs of these words shared a vowel and final consonant, and their vowels were pronounced differently (e.g. sew, few and mad, wad). The two sets of words are listed in the Appendix. These sets were used to select 10 similar and 10 dissimilar lists that were sampled without replacement so that no word appeared more than once and in no more than one list.

\section{Apparatus and Procedure}

The repeated word lists were presented to 16 subjects and the novel word lists to 16 other subjects using Psychlab (Gum \& Bub, 1985) on Macintosh computers programmed to present similar and dissimilar lists in a different random order to each subject. The words were presented successively at a 1-sec rate in the center of the screen. They were shown in bold New York 24-point typeface in black against a white window set in a gray background. After the fifth word, the subjects were required to recall the list by writing the words they could remember in a column numbered 1 to 5 , which indicated the word's serial position in the list. The subjects were instructed to write each word next to the number indicating its po- sition in the list. When recall was finished, the subjects initiated presentation of the next list by a keypress on the computer keyboard. The 20 word lists were preceded by 2 practice lists of five words given to familiarize the subjects with the task requirements. The subjects were instructed that only words recalled in their appropriate serial position would be scored correct. The subjects were tested in groups of 3 to 5 in a computer laboratory equipped with individual Macintosh computers.

\section{Results}

Mean percent correctly recalled words in similar and dissimilar lists of repeated and new words are shown in Table 1. An analysis of variance (ANOVA) in which phonological similarity (similar, dissimilar) was a withinsubject factor and list type (repeated, new words) was a between-subject factor yielded the following results. Recall was significantly lower for phonologically similar lists than it was for dissimilar lists of words $[F(1,30)=140.9$, $\left.M S_{\mathrm{e}}=15.68, p<.001\right]$. Recall levels did not differ significantly for repeated and new word lists. However, the interaction between phonological similarity and list type was significant $\left[F(1,30)=23.6, M S_{\mathrm{e}}=15.68, p<\right.$ $.001]$. This interaction is attributable to the lower level of recall for new dissimilar words than for repeated dissimilar words $[t(60)=2.78, p<.01]$; recall of new similar words did not differ significantly from recall of repeated similar words. Thus, the effect of phonological similarity was highly significant for both repeated word lists $[t(30)=11.8, p<.001]$ and new word lists $[t(30)$ $=4.96, p<.0011$.

Since it has been reported that the phonologicalsimilarity effect arises only when item and order information are required (Watkins, Watkins, \& Crowder, 1974), recall was also scored according to words correctly recalled regardless of their order. The mean percent correct recall in each condition is shown in Table 1 . As is evident when the results of the two methods of scoring are compared, recall levels were higher when order was

Table 1

Mean Percent Recall of Words from Phonologically Similar and Dissimilar Lists of Repeated and New Words in Experiment 1

\begin{tabular}{ccc}
\hline & \multicolumn{2}{c}{ Phonologically } \\
\cline { 2 - 3 } List Words & Similar & Dissimilar \\
\hline
\end{tabular}

Recall of Words in Correct Order

$\begin{array}{lll}\text { Repeated } & 62 & 95\end{array}$

Recall of Words Regardless of Order

$\begin{array}{lll}\text { Repeated } & 77 & 96 \\ \text { New } & 77 & 85\end{array}$

$\begin{array}{lcc} & \text { Recall on Initial Trials } \\ \text { Repeated } & 61 & 94 \\ \text { New } & 68 & 85\end{array}$

Recall on Final Trials

$\begin{array}{lll}\text { Repeated } & 63 & 96\end{array}$

$\begin{array}{lll}\text { New } & 67 & 83\end{array}$ 
disregarded, and the benefit is largely confined to the phonologically similar word lists. However, phonologically similar lists were still significantly less well recalled than were dissimilar lists $\left[F(1,30)=154.1, M S_{\mathrm{e}}=5.18\right.$, $p<.001$ ] . Repeated word lists were better recalled than were new word lists $\left[F(1,30)=4.01, M S_{\mathrm{e}}=31.56, p\right.$ $=.05]$. There was also a significant interaction between list type and phonological similarity $[F(1,30)=22.31$, $M S_{\mathrm{e}}=5.18 . p<.001$ ]. Simple main effects tests showed that the phonological-similarity effect was significant for both repeated $[t(30)=12.12, p<.001]$ and new $[t(30)$ $=4.38, p<.01]$ word lists. As in the previous analysis, the interaction arose because repeated dissimilar words were significantly better recalled than were new dissimilar words $[t(30)=3.63, p<.01]$. Thus, the phonological-similarity effect is not solely due to an increase in order errors in recall.

The extent to which proactive interference from earlier lists causes poorer recall of phonologically similar lists was examined in an analysis of recall on early and late trials. Recall on the first two lists of each type was compared with recall on the last two lists of each type for both repeated and new word lists. For this analysis, words were scored as correct only if reported in their correct serial position. The mean percent correct recall for each condition is shown in Table 1 . These means indicate that the inferior recall of phonologically similar lists was evident even on the first two lists and that recall levels did not alter over trials. An ANOVA indicated a highly significant effect of phonological similarity $[F(1,30)=65.3$, $\left.M S_{\mathrm{e}}=3.03, p<.001\right]$. The levels of recall did not differ significantly for initial and final trials, nor did they differ for repeated and new word lists. The only significant interaction was that between phonological similarity and word repetition $\left[F(1,30)=7.25, M S_{\mathrm{e}}=3.03, p<.02\right]$. Again, as in the previous analysis, this interaction arose because recall on dissimilar new word lists was inferior to that on dissimilar repeated word lists.

Table 2 shows the distribution of the various types of memory errors made on the four types of lists. The main differences between repeated and new word lists were that word-order errors and prior-list intrusions were more frequent with repeated word lists than with new word lists. Omissions were somewhat more common with new word lists than with repeated word lists. Errors not falling into

Table 2

Types of Errors in STM Recall in Experiment 1

\begin{tabular}{lcccc}
\hline & \multicolumn{3}{c}{ Type of Error } \\
\cline { 2 - 4 } \multicolumn{1}{c}{ List } & Omission & $\begin{array}{c}\text { Word } \\
\text { Order }\end{array}$ & $\begin{array}{c}\text { Prior List } \\
\text { Intrusions }\end{array}$ & $\begin{array}{r}\text { Total } \\
\text { Errors }\end{array}$ \\
\hline \multicolumn{5}{c}{ Phonologically Similar } \\
Repeated & $14 \%$ & $43 \%$ & $24 \%$ & 304 \\
New & $30 \%$ & $26 \%$ & $10 \%$ & 248 \\
& \multicolumn{5}{c}{} \\
Repeated & $28 \%$ & $28 \%$ & $23 \%$ & 39 \\
New & $33 \%$ & $15 \%$ & $6 \%$ & 137 \\
\hline
\end{tabular}

the categories in Table 2 constituted only $4 \%-6.5 \%$ of errors for each of the four types of lists.

\section{Discussion}

The results clearly demonstrated that phonologically similar lists are more difficult to recall than are dissimilar control lists. This was also found to be the case when list words were new on every trial and not repeatedly sampled from a small, fixed pool of 8 or 10 words. The possibility that proactive interference between lists is partly the cause of the inferior recall of similar lists was examined by comparing list recall on early and later lists. This comparison indicated quite clearly that the decrement in recall of phonologically similar lists was present at the outset and did not alter in magnitude over subsequent lists. It is apparent that when lists must be recalled in order, phonological similarity impairs recall, and this effect is not dependent on repeated presentation of words selected from a small set.

The detrimental effect of phonological similarity is partly attributable to the requirement that order as well as item information be retained and reproduced in recall. This is indicated by the fact that order errors in recall occurred and by the higher recall scores when order is disregarded. However, for both repeated and new word lists, phonologically similar words were still harder to recall than were dissimilar words. The fact that phonologically similar lists were less well recalled than were dissimilar lists eliminates an explanation in terms of the differential success of guessing for similar and dissimilar lists. With repeated lists, partial information about a list word, for example, one of its phonemes, will enable a subject to generate the correct word for most of the dissimilar words, for example, the word ending with " $y$ " must have been "day." Such a strategy will have a lower probability of success for similar words more of whose phonemes overlapped. The superior recall of repeated dissimilar lists compared with new dissimilar lists could be attributed to the use of the guessing strategy just described. Thus, if a subject remembers that the fourth word began with "h," then that word must have been "hot," the only word from the set that began with "h." In contrast, for new word lists, the information that a list word began with " $h$ " is insufficient to indicate which of all possible threeletter words beginning with " $h$ " it might have been, except that it cannot be a word that has already occurred in a prior list.

\section{EXPERIMENT 2}

The fact that the word-length effect was also obtained when words were new on every trial and that it was not abolished by concurrent articulation led La Pointe and Engle (1990) to speculate that a different type of phonological code is used when words are new on every trial. If that is so, then concurrent articulation might not abolish the phonological-similarity effect when words are new on every trial. With visually presented lists sampled from 
a small pool of words, concurrent articulation does abolish the phonological-similarity effect (Murray, 1968). Consequently, Experiment 2 investigated the effects of concurrent articulation on recall of phonologically similar and dissimilar lists when the list words were new on every trial or repeatedly sampled from a small set. If presentation of new words on every trial induces a different form of phonological encoding from that used with repeated familiar words, then this code might survive concurrent articulation just as the word-length effect did under the same conditions in La Pointe and Engle's (1990) experiments. If, on the other hand, the phonologicalsimilarity effect and the word-length effect arise from different sources, as previously claimed (Baddeley, 1986), then the phonological-similarity effect might be abolished by concurrent articulation whether list items are new or not. The rationale for this prediction is that concurrent articulation was assumed to interfere with phonological recoding of visually presented words' enabling registration in a phonological short-term store, whereas the wordlength effect was attributed to limits on the capacity of the rehearsal loop.

\section{Method}

\section{Subjects}

Forty first-year undergraduates who participated in experiments for course credit acted as subjects. Half were tested with repeated word lists, and half were tested with new word lists.

\section{Stimulus Materials}

The memory task used the phonologically similar and dissimilar word lists from Experiment 1. As in Experiment 1, half the subjects were presented with lists containing new words on every trial and half the subjects had lists sampled from a small pool of eight words.

\section{Apparatus and Procedure}

The subjects were presented lists in a different random order separately determined as in Experiment 1 and had to write down recall on sheets marked with serial positions of list items. The stimuli were presented exactly as in Experiment 1 except that the subjects were individually tested. The subjects were required to count aloud repeatedly from 1 to 6 during list presentation and were given some practice in counting as well as practice lists. Recall occurred in silence. Pilot testing indicated that it was possible to count to 5 about six or seven times during the presentation of a single list. The subjects were told this, and their rate of counting was monitored by the experimenter, who found that the subjects counted to 6 between five and seven times for each list. The experimenter prompted the subjects if they slowed down.

\section{Results}

Mean percent correct recall for the various types of lists is shown in Table 3. It is evident in this table that recall under concurrent articulation was substantially lower than it was in silence in Experiment 1. Recall ranged from $43 \%$ to $54 \%$ correct, and an ANOVA with list type (repeated, new words) as a between-subject factor and phonological similarity (similar, dissimilar) as a within-subject factor showed no significant main effects of either list type $\left[F(1,38)=2.33, M S_{\mathrm{e}}=122.5, p>.13\right]$ or phonologi-
Table 3

Mean Percent Recall of Words from Phonologically Similar and Dissimilar Lists of Repeated and New Words in Experiment 2

\begin{tabular}{|c|c|c|}
\hline \multirow[b]{2}{*}{ List Words } & \multicolumn{2}{|c|}{ Phonologically } \\
\hline & Similar & Dissimilar \\
\hline \multicolumn{3}{|c|}{ Recall of Words in Correct Order } \\
\hline Repeated & 48 & 54 \\
\hline New & 43 & 43 \\
\hline \multicolumn{3}{|c|}{ Recall of Words Regardless of Order } \\
\hline Repeated & 66 & 68 \\
\hline New & 53 & 52 \\
\hline \multicolumn{3}{|c|}{ Recall on Initial Trials } \\
\hline Repeated & 41 & 48 \\
\hline New & 38 & 34 \\
\hline \multicolumn{3}{|c|}{ Recall on Final Trials } \\
\hline Repeated & 49 & 55 \\
\hline New & 48 & 43 \\
\hline
\end{tabular}

cal similarity $\left[F(1,38)=2.36, M S_{\mathrm{e}}=19.7, p>.12\right]$ and no significant interaction between them $[F(1,38)=$ 2.06, $p>.15]$. Thus, lists of repeated words were no better recalled than were lists of words new on every trial, and there was no difference in recall of phonologically similar and dissimilar words.

Analysis of recall scores with order disregarded was also performed. The mean percent correct recall for each condition is shown in Table 3. As in Experiment 1, when order was disregarded, recall scores were higher (52\%-68\%). An ANOVA revealed significantly better recall for repeated word lists than for new word lists $\left[F(1,38)=13.66, M S_{\mathrm{e}}=79.1, p<.001\right]$. There was no effect of phonological similarity $(F<1)$ and no interaction between phonological similarity and list type $(F<$ 1). Thus, when order was disregarded and only item accuracy was scored, there was no trace of a phonologicalsimilarity effect. However, recall for repeated word lists was significantly better than it was for new word lists.

Finally, as in Experiment 1, recall of the first two lists and the last two lists of each type was compared. The mean percent correctly recalled words in correct order for each condition is shown in Table 3. An ANOVA showed no significant difference between the list types $\left[F(1,38)=2.38, M S_{\mathrm{e}}=9.12, p>.12\right]$ and no effect of phonological similarity $(F<1)$. Significantly more words were recalled on the last two trials $(48.5 \%)$ than on the first two trials $(40 \%)\left[F(1,38)=8.27, M S_{\mathrm{e}}=\right.$ $3.39, p<.01]$. Although none of the interactions were significant, the $F$ value for the interaction between list type and phonological similarity was quite substantial in this analysis $\left[F(1,38)=3.64, M S_{\mathrm{e}}=3.17, p<.10\right]$. This interaction was not significant in any of the other analyses based on the full recall data set and should be viewed with caution. Thus, the analysis comparing recall on early and late trials yielded one clear effect: the subjects' recall improved. This suggests that subjects must to some 
extent adapt to the dual task demands imposed by concurrent articulation and that recall is less impaired over time; however, the improvement is quite slight, not correlated with list type, and the overall level of recall (48.5\%) is much lower than the $77 \%$ (average of all lists) found in Experiment 1.

\section{Discussion}

It may be noted that the lower levels of recall found when the subjects were concurrently articulating is primarily caused by a much higher level of omissions. Even the increase in recall when order of report is disregarded is partly attributable to omissions. The subjects commonly recalled about two or three words from the list, but failed to leave sufficient blanks for missing words on their response sheets. Thus, a subject might have recalled Words 1,3 , and 4 but have written Words 3 and 4 in Positions 2 and 3 . Words 3 and 4 were not credited when recall only was scored as correct, only when serial position was also correct. When order was disregarded, these words were counted as correct, as were list transpositions. Comparing recall levels between Experiments 1 and 2 shows that even when order is ignored, recall in Experiment 2 was much lower for dissimilar lists. This lower level of performance was only partly attributable to inaccurately recalled words (e.g., jog instead of jig) and prior list intrusions and was largely due to a paucity of recall, as stated above.

\section{GENERAL DISCUSSION}

Experiments 1 and 2 yielded the following findings. In Experiment 1, it was observed that phonological similarity of list words lowered recall, both when words were repeatedly sampled from a small pool and when words were new on every trial. In Experiment 2, it was found that concurrent articulation both lowered recall and abolished the phonological-similarity effect when list words were repeatedly sampled from a small, fixed pool. This confirmed previous findings on the effects of concurrent articulation (e.g., Murray, 1968). Concurrent articulation also lowered recall and eliminated the phonological-similarity effect when lists contained new words on every trial. This pattern of results differs from that found when word length and list word set are manipulated (La Pointe \& Engle, 1990). The word-length effect (better recall of short than of long words) was obtained both when list words were repeated and when they were new on every trial, but this effect was abolished by concurrent articulation only for the repeated words chosen from a small set. The results of Experiment 2 support arguments (e.g., Baddeley, 1986) that the phonologicalsimilarity effect arises from confusion of similar traces in a phonological short-term store, whereas the wordlength effect is caused by limits on the capacity of a rehearsal system. Recently, it has been shown that output interference and/or limitations are partly responsible for the word-length effect (Avons, Wright, \& Pammer, in press; Henry, 1991). However, it must also be recognized that the word-length effects described above were obtained by La Pointe and Engle (1990) with a memory-span procedure (successive trials with increasing list lengths) and that most of the previous research on phonological similarity and word length has used a fixed list length of (usually) five items. The span procedure lessens the output demands on early trials because initial lists are short. This could be expected to lessen word-length effects, but there is no obvious reason why the span procedure per se should interact with the word-pool variable as it did in La Pointe and Engle's (1990) Experiments 4 and 5, in which serial recall was required. The following rather speculative explanation of the word-length effect with new words and concurrent articulation is offered. With concurrent articulation, phonological encoding of visual stimuli and rehearsal are minimized and recall is largely based on orthographic and unelaborated semantic codes (given the 1-sec presentation rates); such codes are likely to be more difficult to establish for polysyllabic than for monosyllabic words. Words from repeated word lists have, through repetition, had greater opportunities for their orthographic and semantic codes to be established.

The fact that phonological similarity exerts as powerful an influence when words are new on every trial as when they are not is important as it indicates a more pervasive influence of phonological coding in short-term memory than hitherto has been recognized. Phonological coding was thought to be important when order information had to be retained but item encoding was minimal as the item pool was familiar and, in many experiments, on view throughout the task. The results on new word lists reported here indicate that phonological coding is used when item information must be fully encoded along with order. These results strengthen some of the claims made for the functioning of the phonological short-term store and the articulatory rehearsal system in the encoding of other newly encountered verbal items, namely, that these systems are involved in vocabulary acquisition by young children (Gathercole \& Baddeley, 1989), in secondlanguage acquisition by adults (Baddeley, Papagno, \& Vallar, 1988), and in the retention of information that must be integrated between successive eye fixations in reading (Pollatsek, Lesch, Morris, \& Rayner, 1992).

\section{REFERENCES}

Avons, S. E., WRight, K. L., \& PAMmer, K. (in press). The word length effect in probed and serial recall. Quarterly Joumal of Experimental Psychology.

BAdDeley. A. D. (1966). Short-term memory for word sequences as a function of acoustic, semantic and formal similarity. Quarterly Journal of Experimenial Psychology, 18, 362-365.

BADDELEY. A. D. (1986). Working memory. Oxford: Oxford University Press.

Baddeley, A. D. Papagno, C., Vallar, G. (1988), When longterm memory depends on short-term storage. Joumal of Memory \& Language, 27, 586-595.

Baddeley, A. D., Thomson, N., Buchanan, M. (1975). Word length and the structure of short-term memory. Joumal of Verbal Leaming \& Verbal Behavior, 14, 575-589. 
Bavelier, D., \& Potter, M. C. (1992). Visual and phonological codes in repetition blindness. Journal of Experimental Psychology: Human Perception \& Performance, 18, 134-147.

Besner, D., \& DavelaAr, E. (1982). Basic processes in reading: Two phonological codes. Canadian Journal of Psychology, 36, 701-711.

Bishop, D. V. M., \& RoBson, J. (1989). Unimpaired short-term memory and rhyme judgement in congenitally speechless individuals: Implications for the notion of articulatory coding. Quarterly Journal of Experimental Psychology, 41A, 123-141.

Coltheart, V., Avons, S. E., \& Trollope, J. (1990). Articulatory suppression and phonological codes in reading for meaning. Quarterly Joumal of Experimental Psychology, 42A, 375-399.

ConRad, R. (1964). Acoustic confusion in immediate memory. British Journal of Psychology, 55, 75-84.

Conrad, R. (1972). Short-term memory in the deaf: A test for speech coding. British Journal of Psychology, 63, 173-180.

ConRad, R., \& Hull, A. J. (1964). Information, acoustic confusion and memory span. British Journal of Psychology, 55, 429-432.

Elus, N. C., \& HenNelly, R. A. (1980). A bilingual word-length effect: Implications for intelligence testing and the relative ease of mental calculation in Welsh and English. British Journal of Psychology, 71, 43-52.

GATHERCole, S., \& BAdDEley, A. D. (1989). Evaluation of the role of phonological STM in the development of vocabulary in children: A longitudinal study. Journal of Memory \& Language, 28, 200-213.

GuM, T., \& BUB, D. (1985). Psychlab [Computer program]. Montreal: Montreal Neurological Institute.

Henry, L. A. (1991). The effects of word length and phonemic similarity in young children's short-term memory. Quarterly Journal of Experimental Psychology, 43A, 35-52.

Hitch, G. J., \& Haluday, M. S. (1983). Working memory in children. Philosophical Transactions of the Royal Society of London: Series $B, 302,325-340$.

Hitch, G. J., Halliday, S., Schaafstal, A. M., \& Schraagen, J. M. C. (1988). Visual working memory in young children. Memory \& Cognition, 16, 120-132.

KANWISHER, N. G. (1987). Repetition blindness: Type recognition without token individuation. Cognition, 27, 117-143.

Kanwisher, N. G., \& PotTer, M. C. (1990). Repetition blindness: Levels of processing. Journal of Experimental Psychology: Human Perception \& Performance, 16, 30-47.

KuČERA, H. FranCIS, W. N. (1967). Computational analysis of present-day American English. Providence, RI: Brown University Press. LA Pointe, L. B., \& Engle, R. W. (1990). Simple and complex word spans as measures of working memory capacity. Joumal of Experimental Psychology: Learning, Memory, \& Cognition, 16, 1118-1133.
MonSELL, S. (1987). On the relation between lexical input and output pathways for speech. In A. Allport, D. MacKay, W. Prinz, \& E. Scheerer (Eds.), Language perception and production: Relationships between listening, speaking, reading and writing (pp. 273-311). London: Academic Press.

MuRRaY, D. J. (1968). Articulation and acoustic confusability in shorterm memory. Journal of Experimental Psychology, 78, 679-684

Pollatsek, A., Lesch, M., Morris, R. K., \& Rayner, K. (1992). Phonological codes are used in integrating information across saccades in word identification and reading. Journal of Experimental Psychology: Human Perception \& Performance, 18, 148-162.

Stigler, J. W., Lee, S.-Y., \& Stevenson, H. W. (1986). Digit memory in Chinese and English: Evidence for a temporally limited store. Cognition, 23, 1-20.

Watkins, M. J., Watkins, O. C., \& Crowder, R. G. (1974). The modality effect in free and serial recall as a function of phonological similarity. Journal of Verbal Learning \& Verbal Behavior, 13, 430-447.

WICKELGREN, W. A. (1965). Short-term memory for phonemically similar lists. American Joumal of Psychology, 78, 567-574.

\section{APPENDIX}

\section{Words Used in New Word Lists}

Phonologically Similar

rat, lap, tab, fad, nan, sap, yam, cab, fan, cad, nap, jab, can, dad, ham, lab, bat, lad, sat, ban, pad, gap, mad, nab, cat, hat, van, sax, mat, pan, bag, rap, gag, ram, map, wax, lag, tax, dam, tag, lax, jam, had, tap, pat, man, sad, gab, dab, cap

Phonologically Dissimilar

few, joy, tic, vat, bar, gal, mop, rob, dux, rib, gel, cur, ham, dim, sup, hem, day, vet, beg, don, win, mix, rum, web, jig, hot, bid, zip, cow, rag, bus, pit, jaw, mud, jug, fed, wan, god, pen, nap, nut, fad, cox, low, hub, tab, sew, his, fog, fir

(Manuscript received July 27, 1992; revision accepted for publication February 1, 1993.) 